Edvin Dervišević

UDK 811.134.3'34:811.163.6

Študent Univerze v Portu

DOI: 10.4312/vestnik.11.137-150

Portugalska

edvin.dervisevic94@gmail.com

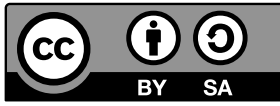

\title{
PREDSTAVITEV POTENCIALNIH FONOLOŠKIH TEŽAV SLOVENSKIH GOVORCEV PRI UČENJU PORTUGALŠČINE KOT TUJEGA JEZIKA
}

UVOD

Fonetika in fonologija portugalskega jezika je področje, s katerim je slovenski jezikovni prostor zaenkrat še razmeroma slabo seznanjen. Najprej se je potrebno zavedati, da kadar govorimo o fonetiki in fonologiji portugalskega jezika, ob tem ločujemo več različic portugalščine, med njimi dve poglavitni (evropsko in brazilsko portugalščino), katerih fonetika in fonologija se izjemno razlikujeta. $\mathrm{V}$ tem članku bo pozornost namenjena fonološkemu sistemu evropske portugalščine v opoziciji do slovenske.

Namen članka je sprva v grobem predstaviti fonološki sistem slovenskega in portugalskega jezika, tako vsakega posebej kot komparativno, ter nato predvideti in opozoriti na morebitne vidnejše fonetične in fonološke težave, s katerimi bi se govorci slovenščine kot maternega jezika lahko srečali pri učenju portugalščine kot tujega jezika (pri tem je poudarek na evropski različici portugalščine). Ob tem bodo predstavljene glavne razlike in odstopanja med enim in drugim fonološkim sistemom, pri čemer bo pozornost usmerjena predvsem na primere, ki bi slovenskim govorcem lahko povzročali največ težav pri prepoznavanju, razumevanju posebnosti portugalskega fonološkega sistema s poudarkom na izgovorjavi posameznih portugalskih fonemov, kar lahko služi tudi kot ustrezen model profesorju portugalščine pri prepoznavanju fonoloških ovir in dvomov pri slovenskih učencih ali študentih portugalščine kot tujega jezika ter odpravljanju le-teh.

\section{2}

\section{TEORETSKA IZHODIŠČA}

Za lažje razumevanje fonoloških razlik in podobnosti med jezikoma je najprej potrebno v grobem predstavitvi splošne karakteristike obeh fonoloških sistemov, slovenskega in portugalskega. 


\subsection{Slovenski fonološki sistem}

Slovenski jezik ima 29 fonemov, med katerimi je 8 samoglasnikov in 21 soglasnikov.

\subsubsection{Vokalni sistem}

Slovenski vokalni sistem vsebuje osem fonemov: /i/,/e/, /E/, /o/, /a/,/o/,/o/,/u/. Vsi samoglasniki se pojavljajo tako v naglašenih kot nenaglašenih pozicijah, čeprav se /e/ ter /o/ redko pojavljata na nenaglašenih mestih (Šuštaršič, Komar \& Petek 1999: 137).

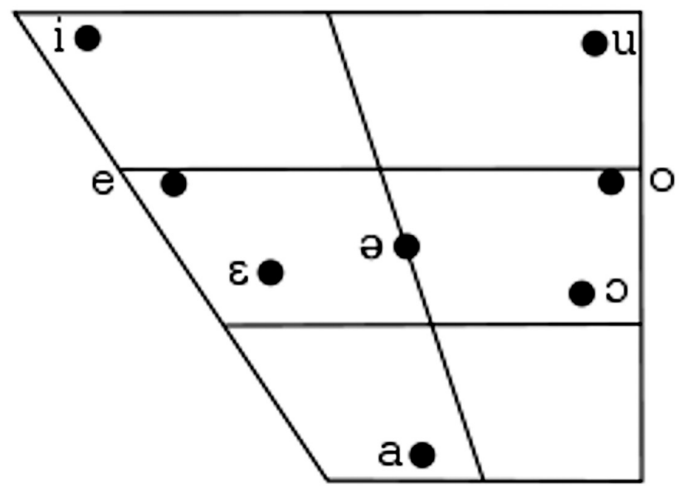

Slika 1: Slovenski vokalni sistem

Tabela 1: Naglašenost in nenaglašenost slovenskih samoglasnikov (Šuštaršič, Komar \& Petek: 137):

\begin{tabular}{|c|c|}
\hline Naglašeni samoglasniki & Nenaglašeni samoglasniki \\
\hline $\mathrm{i}:$ mi:t mit & i 'mi:ti miti \\
\hline e: me:t med & e ze've: že ve \\
\hline$\varepsilon:$ 'p $\varepsilon$ :ta peta & $\varepsilon$ 'pe:te pete \\
\hline a: ma:t mat & a 'ma:ta mata \\
\hline ๑: 'p ə:ten poten & o po'te:m potem \\
\hline o: po:t pot & o bo’ flo bo šlo \\
\hline $\mathrm{u}:$ pu:st pust & u 'pu:stu pustu \\
\hline ə: pə:s pes & ə 'do:bər dober \\
\hline
\end{tabular}

\section{Dvoglasniki v slovenščini}

Poleg enoglasnikov pa ima slovenščina tudi dvoglasnike oz. diftonge. Ti se vzpostavijo $\mathrm{v}$ poziciji, kjer pred $/ \mathrm{j} /$ in $/ \mathrm{v} /$ stoji samoglasnik na koncu zlogov in pred soglasniki. Zato ju v takšnih pozicijah posledično izgovarjamo kot prava samoglasnika/i/ in /u/, ki skupaj s predstoječim samoglasnikom tvorita diftong (Šuštaršič, Komar \& Petek 1999: 137). 
Tabela 2: Diftongi v slovenščini (Šuštaršič, Komar \& Petek 1999: 137):

\begin{tabular}{|l|l|l|}
\hline ei & glei & glej \\
\hline ai & dai & daj \\
\hline oi & tvoi & tvoj \\
\hline oi & boi & boj \\
\hline ui & tui & tuj \\
\hline iu & piu & pil \\
\hline eu & peu & pel \\
\hline cu & leu & lev \\
\hline au & pau & pav \\
\hline ou & pou & pol \\
\hline ou & 'to:pəu & topel \\
\hline
\end{tabular}

\subsubsection{Soglasniški sistem}

Slovenščina ima 21 soglasnikov, ki se glede na odprtostno stopnjo delijo na zvočnike in nezvočnike. Nezvočniki se nato delijo še na zveneče in nezveneče.

a) zvočniki po mestu ožine so: nosna in ustna $/ \mathrm{m} /$ ter $/ \mathrm{n} /$ ter ustni; drsna $/ \mathrm{v} / \mathrm{in} / \mathrm{j} /$, jezični nepretrgani /1/ in jezični pretrgani /r/

b) nezvočnike delimo na zapornike (p-b, t-d, k-g), pripornike (f, s-z, š-ž in h) ter zlitnike (c, č in dž).

Glede na način izgovora nezvočnike delimo na zveneče (g, d, z, b, ž, dž) in nezvene-

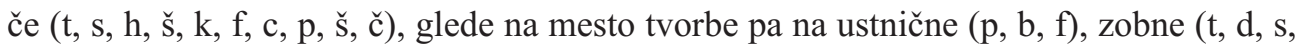
z, c), zadlesnične ( $\breve{s}, \breve{z}, \breve{c}, d z ̌)$ ter mehkonebne (k, g, h) (Toporišič 2000: 73-82).

\subsection{Fonološki sistem evropske portugalščine}

\subsubsection{Vokalni sistem}

Vokalni sistem portugalskega jezika spada med kompleksnejše in bogatejše fonološke sisteme romanskih jezikov. Poleg ustnih samoglasnikov (prisotnih v slovenščini) ima portugalščina nosne samoglasnike oz. nosnike, dvoglasnike in celo troglasnike. Evropska portugalščina obsega devet ustnih samoglasnikov: /i/, /e/, / / /, /a/, /e/, /a/, /u/, /o/, /o/ in

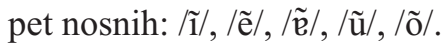




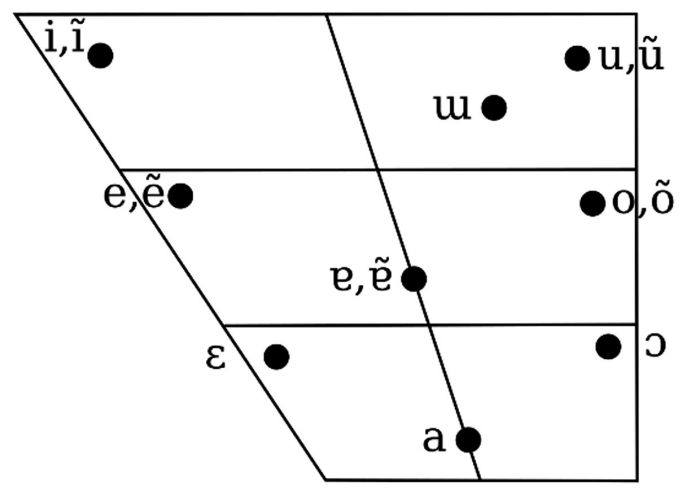

Slika 2: Vokalni sistem evropske portugalščine

Portugalska slovnica Nova Gramática do Português Contemporâneo portugalske samoglasnike deli v naslednje skupine (Cunha, Cintra 1984: 36-40):

a) Naglašeni ustni samoglasniki:

Zaprti: /i/, /u/

Polzaprti: /e/,/e/,/o/

Polodprti: /ع/, /o/

Odprti: /a/

Primeri: li / lêe, pé / pá, saco / soco, poça / possa, todo / tudo

amamos /e'memuf/ - amámos /e'mamuf/

b) Naglašeni nosni samoglasniki:

Zaprti: / $\tilde{1} /, / \tilde{\mathrm{u}} /$

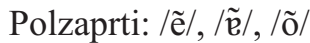

Primeri: rim, senda, canta, lã, bomba, atum.

c) Nenaglašeni ustni samoglasniki:

\section{V nenaglašeni nekončni poziciji:}

$\mathrm{V}$ evropski portugalščini se na nenaglašenem nekončnem mestu splošno pojavlja sredinski ali centralni samoglasnik /ə/, ki se ne kaže v naglašenih pozicijah. Vrsta zadnjih ali velarnih samoglasnikov je reducirana $\mathrm{v}$ fonem /u/, ki ga v zapisu predstavljata črki $o$ ali $u$. Na drugi strani pa sredinskemu ali centralnemu, odprtemu samoglasniku /a/ ustreza prav tako sredinski ali centrali, temveč polzaprti /e/, ki v grafiji ustreza črki $a$.

Zaprti: /i/, /ə/, /u/

Polzaprti: /e/

Primeri: ligar /li'gar/, legar /lo'gar/, lagar /ln'gar/, lograr /lu'grar/, véspera /'vefpara/, diálogo /di'alugu/. 


\section{V absolutni končni poziciji:}

V absolutni končni poziciji pa sprednji ali palatalni niz izgine in se na tem mestu pojavi samoglasnik /ə/, označen s črko $e$. Medtem pa se zadnji ali velarni niz reducira v samoglasnik/u/, ki je v grafiji reprezentiran s črko $o$.

Zaprti: /ə/, /u/

Polzaprti: / $\mathfrak{e} /$

Primeri: tarde /'tardo/, povo /'povu/, casa /'kazp/.

Tabela 3: Primeri samoglasnikov evropske portugalščine (Cruz-Ferreira 1999: 127):

\begin{tabular}{|c|c|}
\hline Ustni samoglasniki & Nosni samoglasniki \\
\hline i vi vi $(1 \mathrm{sg})$ & ĩ vĩm vim \\
\hline e ve $v \hat{e}(3 \mathrm{sg})$ & ẽ 'ẽtru entro \\
\hline$\varepsilon$ se $s e ́$ & $\tilde{\mathrm{e}}$ 'êtru antro \\
\hline a va vá $(3 \mathrm{sg})$ & õ sõ som \\
\hline o so só & ũ 'mũdu mundo \\
\hline o so sou & \\
\hline $\mathrm{u}$ 'mudu mudo & \\
\hline в pe'gar pagar & \\
\hline ә pə'pag pegar & \\
\hline
\end{tabular}

\section{Ustni in nosni diftongi}

Tako kot samoglasniki so tudi dvoglasniki oz. diftongi lahko ustni ali nosni glede na ustno ali nosno naravnanost. V fonološkem sistemu evropske portugalščine obstaja 14 dvoglasnikov, med katerimi je deset ustnih in štirje nosni (Cunha, Cintra 1984: 48-50):

Ustni padajoči diftongi:

\begin{tabular}{|l|l|l|l|l|}
\hline$/$ aj/: pai & $/$ ej/: sei & $/ a w /:$ mau & $/ \varepsilon j /:$ papéis & $/$ ew/: meu \\
\hline$/ \varepsilon u /:$ céu & $/$ iw/: viu & $/$ oj/: boi & $/$ jj/: herói & $/$ uj/: azuis \\
\hline
\end{tabular}

Nosni padajoči diftongi:

\begin{tabular}{|c|c|}
\hline 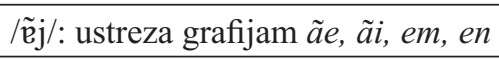 & mãe, cãibra, vem, levem, benzinho \\
\hline 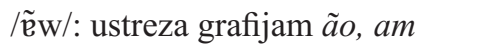 & mão, vejam \\
\hline /õj/: ustreza grafiji õe & põe, sermões \\
\hline /ũj/: ustreza grafiji $u i$ & muito \\
\hline
\end{tabular}

Poleg rastočih in padajočih dvoglasnikov med samoglasniškimi stiki v portugalščini pa je potrebno omeniti tudi troglasnike, prav tako ustne (kot Uruguai) in nosne (kot denimo saguãu), jate ter intraverbalne in interverbalne stike (Cunha, Cintra 1984: 51). 


\subsubsection{Soglasniški sistem evropske portugalščine}

\section{Klasifikacija soglasnikov}

Portugalski jezik ima 19 soglasnikov, ki jih tradicionalno razvrščamo glede na naslednje štiri kriterije: glede na način izgovora; na okluzivne in konstriktivne, glede na mesto izgovora; na ustničnoustnične (bilabialne), zobnoustnične (labiodentalne), zobne (linguodentalne), zobnojezične (alveolarne), nebnojezične (palatalne) in mehkonebnojezične (velarne), glede na vlogo glasilk; na zveneče in nezveneče ter glede na odprtostno stopnjo ustne ali nosne votline; na ustne ali nosne (Cunha, Cintra 1984: 41-46).

Nakažimo portugalski soglasniški sistem z razvrstitvijo glede na način izgovora soglasnikov.

Med okluzivne spadajo naslednji nosni: $/ \mathrm{m} /, / \mathrm{n} /, / \mathrm{n} /:$ amo, ano, anho ter ustni soglasniki: /p/,/b/,/t/,/d/,/k/,/g/: pala, bala, tala, dá-la, cala, gala.

Znotraj konstriktivnih soglasnikov pa razlikujemo med:

a) frikativnimi: /f/, /v/, /s/, /z/, /f/ in /z/: fala, vala, selo (passo, céu, caça, próximo), zelo (rosa, exame), xarope (encher), já (gelo)

b) lateralnimi: $/ 1 /$ in $/ K /:$ fila, filha

c) vibrirajočimi: /r/ in /R/: caro, carro

\section{3 PREDSTAVITEV POTENCIALNIH TEŽAV PRI DIFERENCIACIJ MED SISTEMOMA}

Kljub temu da govorimo o dveh jezikih, ki sta si v mnogih jezikovnih pogledih povsem tuja, lahko na podlagi predstavljenih osnovnih fonoloških značilnosti obeh jezikov in njunih fonoloških sistemov opazimo mnoge jezikovne podobnosti med slovenščino in portugalščino, tako pri samoglasniškem kot soglasniškem sistemu. Podobnosti je moč iskati predvsem v izgovoru samoglasnikov, ustnih diftongov in v pestrosti soglasnikov, zlasti frikativnih, ki sovpadajo s slovenskimi frikativi oz. priporniki.

Vselej pa portugalščina z mnogimi nosnimi samoglasniki in soglasniki ter z obilo soglasniških stikov in kontrakcij mnogim slovenskim govorcem predstavlja velik izziv, pogosto tudi nemalo ovir pri doseganju pravilne izgovorjave.

V nadaljevanju bomo skušali opozoriti na nekatere izmed potencialnih težav.

\section{Izgovor samoglasnika /e/}

Slovenski govorci nimajo nikakršnih težav z izgovorjavo večine portugalskih ustnih (nenosnih) samoglasnikov, samoglasnik / $/$ / pa lahko predstavlja oviro v naslednjih situacijah:

/e/ v naglašeni poziciji: falamos /fat' $\mathrm{Emu} / /$

v nenaglašeni poziciji: nada/'nade/

v poziciji z dvoglasnikom: sei /'sej/ 


\title{
Izgovor nosnih samoglasnikov
}

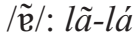

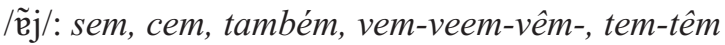

Kot opozarjata in dokazujeta že Müller Pograjc in Markič (Müller Pograjc, Markič 2017: 266-270), bi vse zgoraj navedene oblike, ki vsebujejo nosne samoglasnike oz. nosnike lahko povzročale mnogo težav slovenskim študentom, ki bi se v tem primeru odločali za ustni izgovor samoglasnikov oz. nenosniški (em), namesto ustrezne nosniške izgovorjave

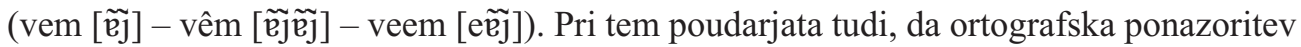
oblik (também, vêm) načeloma ne pripomore k lažji izgovorjavi oz. dejansko ne pomaga slovenskemu študentu pri nazalni artikulaciji, kvečjemu ga ta lahko samo še bolj zmede.

\section{$/ \tilde{\mathrm{u} j} /:$ muito

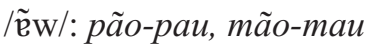 \\ /õj/: corações-canções-relações}

Poleg tega lahko v primeru zgoraj navedenih nosnih diftongov v evropski portugalščini zaznavamo težave pri slovenskem govorcu, ki običajno v izgovoru ne razlikuje med ustnimi ter nosnimi oblikami, saj slovenski vokalni sistem slednjih ne pozna. Slovenski govorec bi tako načeloma vse zgornje pare izgovarjal na enak način, in sicer ustno oz. nenosniško. Vse pa postane še bistveno bolj zapleteno, kadar je nazalnost neke oblike tudi pomensko razločevalna, kot denimo v primerih: mão-mau, pão-pau in je razlikovanje potrebno, sicer lahko pride do morebitnih dvoumnosti in nesporazumov.

Kljub temu da slovenski fonološki sistem pozna diftonge, pa so ti zgolj ustni, medtem ko portugalščina premore tudi nosne diftonge. Slovenski govorec ima zato lahko težave tudi pri izgovorjavi naslednjih glagolskih oblik, ki vsebujejo nosnike, sam pa jih običajno izgovarja kot ustne.

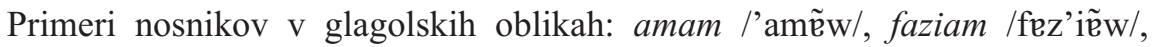
digam /'digẽw/

Medtem ko ustni diftongi slovenskim študentom načeloma ne povzročajo nikakršnih težav:

\section{Primeri: cai /'kaj/, teu /'tew/, fui /'fuj/}

Kot poudarita Markič in Müller Pograjc, izgovorjava nosnih samoglasnikov in diftongov torej lahko predstavlja velik problem za slovenske študente, saj slovenščina nima nikakršnih tovrstnih ustreznic, ki bi govorcem lahko pomagale pri doseganju ustrezne izgovorjave (Müller Pograjc, Markič 2017: 268-270). 
Manj raziskano pa je področje portugalskih soglasnikov in tendence evropske portugalščine po reduciranju vrste samoglasnikov, kar se (za razliko od slovenščine, kjer se redukcije sicer kažejo na pogovorni ravni, najbolj izrazito prav v ljubljanskem govornem okolju) kaže kot norma portugalskega jezika oz. nekaj, kar je skupno standardni evropski portugalščini in ne zgolj eni izmed njenih dialektalnih različic. Na tem področju bo potrebnih več raziskav tudi s poudarkom na soglasniški sistem evropske portugalščine in njegovo pojavnost $\mathrm{v}$ rabi. Zato v nadaljevanju kot problematične in raziskave vredne izpostavljam tudi naslednje karakteristike.

\section{Soglasniška tendenca evropske portugalščine}

Četudi ima slovenščina, kot na splošno velja za slovanske jezike, dobro razvit in pester nabor soglasnikov in soglasniških sklopov, v mnogih situacijah ne sovpada s soglasniškimi variantnostmi evropske portugalščine. V slovenščini so sicer prisotne mnoge redukcije, a predvsem na regionalni ter pogovorni ravni, ne pa tudi sicer na normativni ravni knjižne slovenščine. Mnogi govorci imajo zato lahko težave pri zapiranju, krčenju, reduciranju ali celo popolnem opuščanju mnogih nenaglašenih samoglasnikov v evropski različici portugalskega jezika.

Samoglasnik ə, v slovenščini poznan kot polglasnik, je sicer vseprisoten, a ima v slovenskem jeziku povsem drugačno vlogo, saj se le-ta lahko pojavi tudi v naglašenih pozicijah in nosi naglasno mesto besede, kar se ne zgodi v primeru evropske portugalščine. Poleg tega lahko ponazoritev samoglasnika ə $\mathrm{s}$ črko $e \mathrm{v}$ absolutni končni poziciji besed v evropski portugalščini predstavlja oviro slovenskemu govorcu, ki bi se pri leksemih kakor tarde, vinte ali saudade nagibal k izgovorjavi s končnim odprtim in širokim samoglasnikom - $\varepsilon$.

Poleg tega pa se v evropski portugalščini samoglasnik ə pogosto pojavi kot sredinski ali centralni zaprti samoglasnik v nenaglašeni poziciji sredi besede, kar lahko predstavlja težavo za slovenskega govorca, saj v slovenščini zapis črke $e$ v nenaglašeni poziciji (z izjemo posameznih redukcij v okviru pogovornega jezika) v izgovoru večinoma ustreza odprtim širokim samoglasnikom $\varepsilon$.

Primer portugalskega centralnega zaprtega ə v nenaglašenih pozicijah:

desaparecer /dəzeperə'ser/, perceber /pərsə'ber/, precisar /prəsi'zar/

Vselej pa je mogoče izpostaviti primere, kjer jezika sovpadata in se zapis grafema $e$ v nenaglašeni poziciji v izgovoru kaže s samoglasnikom ə tudi v slovenščini:

pessoa /pə'soa/ $\rightarrow$ analogija s slovenščino: megla /mə'gla/, grelec /gre'ləc/ 


\section{Fonemi zapisov $\boldsymbol{E}$ in $\boldsymbol{O}$ v evropski portugalščini glede na mesto izgovora}

Slovenski govorec načeloma ne bi smel imeti večjih težav pri razlikovanju in izgovorjavi polodprtih in polzaprtih portugalskih samoglasnikov (/ع/- /e/, /o/ - /o/), saj slovenski samoglasniški sistem pozna enako vokalno distinkcijo.

obra /'obra/, bolo /'bolu/ $\rightarrow$ analogija s slovenščino: oče /'ot $\int \varepsilon /$, sonce /'sontse/ ele /'etə/, ela /'ele/ $\rightarrow$ analogija s slovenščino: reka /'reka/, meja /'meja/

Morebitne ovire pa se lahko pokažejo v naslednjih primerih:

a) kjer je samoglasnik /o/ v nenaglašeni poziciji in tako posledično v izgovoru reduciran na $/ \mathrm{u} /$ :

belo /'belu/, toalha /tu'aKe/, somos /'somuf/

b) kjer je črka $e$ v evropski portugalščini ponazorjena $\mathrm{z}$ mnogimi različnimi fonemi in bi slovenski govorec $\mathrm{v}$ spodaj navedenih primerih po naravi običajno napačno izgovarjal vsak zapisan $e$ kot odprti široki samoglasnik / $/$ /:

V začetni opuščeni poziciji: espaço/'`pasu/

Kot centralni zaprti samoglasnik ə v nenaglašeni poziciji: feliz /fə'lif/

V nenaglašeni nekončni poziciji + absolutni končni poziciji: verdade /vər'dadə/

V poziciji s predhodnim nosnikom: põe/'põj/

Kot samoglasnik $i$ v poziciji pred $a$, e ali $u$ : real /Ri'ał/ (candeeiro, reunião)

\section{Mesto in variantnost soglasnikov}

\section{Različice fonema $s$}

Soglasnik /s/ je v portugalščini predstavljen skozi vrsto grafij, kar lahko oteži pravilni izgovor slovenskemu govorcu v jezikovnih kontekstih, kjer se fonem /s/ ne pojavlja preko zapisa s črko $s$, kot to edino poteka v slovenščini. V portugalščini izgovorjavo soglasnika /s/ lahko ponazarja več grafij:

sumo, massa, cento, caça, próximo.

\section{Variantnost grafema $S$}

Zapis črke $s$ je v evropski portugalščini lahko ponazoritev za več fonemov v izgovoru, in sicer:

$$
\text { /s/: sala /'satp/, /z/: peso /'pezu/, /J/: pés /'pěs/ }
$$




\section{Variantnost grafema $X$}

Črka $x$ lahko povzroča precej težav slovenskemu govorcu, saj je le-ta v evropski portugalščini ponazoritev za mnoge foneme v izgovoru:

/J/: freixo /'frejJu/, /z/: exato /i'zatu/, /s/: próximo /pro'simu/, /ks/: taxi /'taksi/

\section{Izgovor soglasnika $l$}

Izgovor soglasnika $l \mathrm{v}$ portugalščini se približuje izgovoru $l$-ja v nekaterih slovanskih jezikih, kar pa ne velja tudi za slovenščino. ${ }^{1}$ Zato je lahko pravilna izgovorjava tega soglasnika pri slovenskih govorcih nekoliko otežena.

V začetni ali medsamoglasniški poziciji: levo /'levu/, vela /'vele/

V končni poziciji posameznega zloga ali besede: /t/ - alto /'attu/, sol /'sot/

\section{Razločevalna soglasnika $r$ in $R$}

Fonem /r/: caro Fonem /R/: carro, rua

V evropski portugalščini smo priča dvema različnima soglasnikoma: preprosti apikalni $/ \mathrm{r} /$ ter večdelni vibrirajoči uvularni /R/. Oba fonema sta $\mathrm{v}$ zapisu zaznamovana in ponazorjena s črko $r$, medtem ko slovenski fonološki sistem vključuje zgolj en sam fonem črke $r$. Tako tiste besede, ki v evropski portugalščini vključujejo fonem/r/ (kot na primer caro) kot tiste, ki vsebujejo fonem /R/, bodisi se začenjajo s soglasnikom R (kakor rua) bodisi stojijo $\mathrm{v}$ intervokalni poziciji, kjer dve črki predstavljata en sam fonem $r r$ (kot $\mathrm{v}$ primeru carro), bi bile pri slovenskih govorcih načeloma vse izgovorjene na enak način, in sicer s preprostim apikalnim $r$-jem, kar lahko predstavlja težavo.

\section{Odsotnost fonema / $\mathbf{x}$ / pri grafemu $h$}

Kot pri večini romanskih jezikov se tudi v portugalščini grafem $h \mathrm{v}$ izgovoru opušča oz. ne izgovarja, medtem ko $\mathrm{v}$ slovenščini $\mathrm{v}$ takih situacijah uporabljamo izgovorjavo fonema / $\mathrm{x} /$, kar zapisujemo $\mathrm{z}$ grafijo $h$. Težave se tako lahko pojavijo pri besedah kot so: hoje, horrivel, hora, kjer bi se slovenski govorec nagibal k izgovarjanju črke $h$, in s tem $\mathrm{k}$ uporabi fonema $/ \mathrm{x} /$, kar pa je napačno.

\section{Soglasniški stiki}

Evropska portugalščina poleg že vseh omenjenih posebnosti vsebuje tudi vrsto soglasniških, zlasti sičniških in šumniških stikov. Čeprav bi si morda mislili, da za govorce

1 Portugalščina (zlasti evropska) ima tako kot nekateri slovanski jeziki v izgovoru ohranjen tako imenovani trdi, velarni glas 1/ł/, izgovorjen s središčno zaporo, ki jo napravi sprednja jezična ploskev na mehkem nebu, medtem ko je v knjižni slovenščini prisoten navadni, srednjeevropski /1/. 
nekega slovanskega jezika tovrstni sklopi ne bi smeli predstavljati posebnih naporov in težav, imajo lahko slovenski govorci vselej težavo pri prepoznavanju nekaterih zapisov in povezovanju le-teh v ustrezne foneme na ravni izgovorjave. Šumnika $/ \int / \mathrm{in} / 3 / \mathrm{se} \mathrm{v}$ evropski portugalščini pojavljata v oblikah kot so: três, voz (v finalni poziciji), espelho (v začetni poziciji) ali mesmo (v centralni poziciji). Varianta fonema / $/$ se pojavlja v absolutnih končnih pozicijah kot na primer três in voz ali kadar črki s sledi nezveneči soglasnik, na primer espelho, medtem ko se fonem /3/ pojavlja v situacijah, kadar $s$-ju sledi zveneči soglasnik, kot denimo mesmo.

Slovenski govorec bi se v tovrstnih primerih težko odločil za izgovor šumnikov / $/$ in /3/, ki sta v slovenščini ponazorjena z grafijama $\check{s}$ in $\check{z}$, kar je tudi edini način, ki v slovenščini ponazarja izgovor fonemov $/ \int /$ in /3/. Potemtakem je torej veliko bolj verjetno, da se bo slovenski govorec zaradi naravnanosti lastnega maternega jezika, še zlasti v absolutnih končnih pozicijah besed, v tovrstnih primerih odločil za izgovor sičnikov /s/ in /z/, kar pa sicer ne bi bilo napačno v okviru fonološkega sistema brazilske različice portugalščine.

Poleg omenjenih soglasniških sklopov in skupin pa je potrebno omeniti tudi skupke črk, ki predstavljajo zgolj en fonem oz. en glas. Gre za tako imenovane digrafe oz. dvočrkja in tudi ti lahko povzročajo slovenskim govorcem portugalščine nemalo težav:

$\begin{array}{lll}\text { - } g u: & \text { primer: águia } & g u \rightarrow / g / \\ \text { - } q u: & \text { primer: toque } & q u \rightarrow / k / \\ \text { - lh, } n h & \text { primera: velho, tenho } & l h \rightarrow / K / \quad n h \rightarrow / \mathrm{n} /\end{array}$

$L h$ in $n h$ sta digrafa, ki v portugalščini vsak posebej predstavljata zgolj en sam fonem oz. glas - $/ K /$ in $/ \mathrm{n} /$. Ob tem je potrebno poudariti, da v slovenščini ne obstajata fonema $/ K /$ in $/ \mathrm{n} /$, obstajajo zgolj ločeni soglasniki $l, n$ in $j$. Vse skupaj pa lahko postane še bolj kompleksno, saj je /n/ nosni, zato zahteva tudi temu primerno nosno izgovorjavo, ki pa je, kot smo lahko videli, vse prej kot enostavna za slovenskega govorca.

V okviru nosniške naravnanosti portugalskih soglasnikov, ki lahko povzročajo težave slovenskim govorcem, je potrebno opozoriti tudi na naslednje digrafe oz. dvočrkja, ki v portugalščini izoblikujejo nosniški izgovor oz. služijo kot ponazoritev nosnih samoglasnikov: am, an, em, en, im, in, om, on, um in un.

Primeri: tampo, tanto, tempo, tento, limbo, lindo, pombo, tonto, comum, mundo.

Po drugi strani pa naslednji primeri, kjer izgovor soglasnikov ne zahteva nosniških prvin, povzročajo bistveno manj težav:

$$
\text { /s/: cedo /'sedu/, ciclo /'siklu/ /3/: gelo /'zelu/, giro /'ziru/, jaula /'zaule/ }
$$


Več težav pa lahko povzročajo naslednji soglasniški stiki različnih vrst.

Soglasniški sklopi $s c, s c ̧$ in $x c$ v intervokalnih pozicijah, kot na primer:

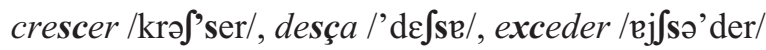

Med govorno realizacijo $\mathrm{v}$ evropski portugalščini pa se sicer pojavljajo tudi drugi samoglasniški in soglasniški sklopi in stiki med ali znotraj posameznih besed, kar lahko prav tako bistveno oteži oz. zaplete način izgovorjave za slovenske govorce.

Soglasniški stiki, nastali z vokalnimi redukcijami, znotraj posameznega leksema:

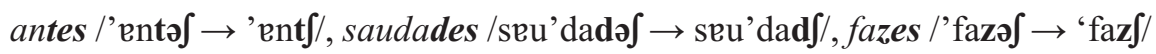

Samoglasniški in soglasniški stiki med več leksemi, kjer pride do sklapljanja med fonemom $\mathrm{v}$ absolutni finalni poziciji leksema in fonemom $\mathrm{v}$ začetni poziciji sledečega leksema:

Stik med dvema soglasnikoma:

às três $/ \mathrm{a} \int$ 'tre $\int \rightarrow \mathrm{a} \int$ 'tre $\int /$, às duas /af 'dur $\int \rightarrow \mathrm{az}$ 'dur $\int /$

Stik med dvema soglasnikoma, ki se zlijeta $v$ enega:

às seis $/ \mathrm{a} \int$ 'skj $\rightarrow \mathrm{a} \int{ }^{\prime} \mathrm{kjj} /$

Stik med soglasnikom in samoglasnikom:

às oito /af 'oitu $\rightarrow \mathrm{az}$ 'oitu/

Na podlagi izpostavljenih predvidevanj je potrebno poudariti, da igra vprašanje portugalskega fonološkega sistema (konkretneje fonološkega sistema evropske portugalščine) $\mathrm{v}$ okviru poučevanja in učenja portugalskega jezika pri slovenskih govorcih in študentih izjemno pomembno vlogo. Tovrstno področje tako vsekakor zasluži več pozornosti ter nadaljnje temeljite raziskave in študije s poudarkom na realizaciji mnogih praktičnih vaj za usvajanje portugalske izgovorjave, pri čemer lahko pomembno pripomorejo tudi fonetični laboratoriji.

Zaključimo lahko, da se poleg izgovorjave nosnih samoglasnikov in diftongov $\mathrm{v}$ evropski portugalščini, ki se vsekakor kažejo kot temeljna fonološka težavnost slovenskih govorcev pri usvajanju portugalskega fonetičnega sistema, kot problematično področje predvidevajo tudi mnogi soglasniški sklopi, prepreke in posebnosti izgovorjave, ki so lastne evropski portugalščini in na katere je potrebno opozoriti ter jih tudi ustrezno ločiti 
od fonoloških značilnosti brazilske različice portugalščine. Tovrstna predvidevanja pa bi kazalo potrditi v prihodnjih raziskavah in analizah. Portugalski fonološki sistem mora s svojo kompleksnostjo in pestrostjo vsekakor predstavljati večji izziv tako slovenskemu govorcu oz. študentu portugalščine kot tudi slovenskemu profesorju portugalščine.

\section{BIBLIOGRAFIJA}

CUNHA, Celso/Luís LINDLEY CINTRA (1984) Nova Gramática do Português Contemporâneo. Lizbona: Edições João Sá da Costa.

CRUZ-FERREIRA, Madalena (1999) Portuguese (European). Handbook of the International Phonetic Association. A Guide to the Use of the International Phonetic Alphabet. Cambridge: Cambridge University Press, 126-130.

MATEUS, Maria Helena Mira/Isabel FALÉ/Maria João FEITAS (2005) Fonética e Fonologia do Português. Lizbona: Universidade Aberta.

MÜLLER POGRAJC, Blažka/Jasmina MARKIČ (2017) Nasal vowels and diphthongs in European Portuguese. Linguistica 57, 261-272.

NUNES, José Joaquim (1989) Compêndio de Gramática Histórica Portuguesa. Lizbona: Clássica Editora.

TOPORIŠIČ, Jože (2000) Slovenska slovnica. Maribor: Založba Obzorja.

TOPORIŠIČ, Jože (1978) Glasovna in naglasna podoba slovenskega jezika. Ljubljana: Založba Obzorja.

TIVADAR, Hotimir (2013) Fonetika in fonologija slovenskega knjižnega jezika. Ljubljana: Filozofska fakulteta Univerze v Ljubljani.

ŠUŠTARŠIČ, Rastislav/Smiljana KOMAR/Bojan PETEK (1999) Slovene. Handbook of the International Phonetic Association. A Guide to the Use of the International Phonetic Alphabet. Cambridge: Cambridge University Press, 135-139.

\section{POVZETEK}

Pojem fonetike in fonologije portugalskega jezika zaobjema široko in obsežno jezikoslovno področje preučevanja mnogih med seboj raznovrstnih fonoloških različic portugalščine, pri čemer kot poglavitni izstopata predvsem evropska ter brazilska različica portugalščine in njuna fonološka sistema. $\mathrm{V}$ prispevku je pozornost usmerjena $\mathrm{k}$ evropski različici jezika ter njenim posebnostim $\mathrm{v}$ primerjavi s slovenščino in slovenskimi fonološkimi značilnostmi. Namen prispevka je sprva opozoriti na glavne podobnosti in razlike med fonološkima sistemoma slovenščine in evropske portugalščine s poudarkom na samoglasniški in soglasniški klasifikaciji obeh jezikov. Nato pa $\mathrm{v}$ osrednjem delu preko predstavitve posameznih primerov predvideti najvidnejše diferenciacije ter ob tem morebitne težave, s katerimi bi se lahko soočili slovenski materni govorci in študentje 
portugalščine kot tujega jezika pri učenju in usvajanju portugalske fonologije, zlasti fonološkega sistema evropske portugalščine. Že raziskano vprašanje fonoloških težav portugalščine za slovenske govorce in študente na ravni usvajanja nosnih samoglasnikov in diftongov, kjer slovenski študentje ne morejo iskati analogije $\mathrm{z}$ maternim jezikom, je $\mathrm{v}$ tem prispevku nadgrajeno $\mathrm{z}$ drugimi fonološkimi posebnostmi, zlasti evropske portugalščine, za katere se predvideva, da bi lahko predstavljale problem slovenskim govorcem in študentom pri učenju, kot je na primer vprašanje soglasnikov in soglasniških sklopov, raznovrstnosti posameznih portugalskih fonemov ter izrazite tendence evropske portugalščine po vokalnih redukcijah.

Ključne besede: evropska portugalščina, slovenščina, fonološki sistem, slovenski govorci portugalščine, potencialne fonološke težave

\section{ABSTRACT \\ Presentation of potential phonological difficulties of Slovene speakers while learning Portu- guese as a foreign language}

The phonetics and phonology of the Portuguese language comprise a wide and extensive linguistic field when studying the many different phonological varieties of Portuguese. European and Brazilian Portuguese generally represent the two principal varieties of the language. The purpose of this article is to emphasize the main similarities and differences between the phonological systems of Slovene and European Portuguese, by introducing the vocal and the consonant classifications of both languages, and to anticipate, by analysing individual examples, the most conspicuous differentiations and potential difficulties that Slovene speakers and students of Portuguese as a foreign language could face while learning Portuguese phonology, particularly the phonological system of European Portuguese. The question of phonological difficulties of Portuguese for Slovene speakers and students in terms of assimilating the nasal vowels and diphthongs, for which Slovene students cannot find any analogies within their mother tongue, has been previously discussed and can now only be extended to other phonological peculiarities (mostly related to the European variety of Portuguese) that could potentially be a significant obstacle to overcome while learning, such as the problem of consonants and consonant clusters, the diversity of particular Portuguese phonemes, as well as a distinct tendency of European Portuguese for vocal reductions.

Keywords: European Portuguese, Slovene, phonological system, Slovene speakers of Portuguese, potential phonological difficulties 